\title{
STUDI ETNOBOTANI SUKU DAYAK RIBUN DALAM PEMANFAATAN TUMBUHAN BERNILAI SENI DI DESA GUNAM KECAMATAN PARINDU KABUPATEN SANGGAU
}

(Etnobotani Study Of Dayak Ribun In The Utilization Of Artificial Plant Growth In Desa Gunam Kecamatan Parindu Sanggau Regency)

\author{
A. Nggadas, M. Idham, L. Sisilia \\ Fakultas Kehutanan Universitas Tanjungpura Jalan Imam Bonjol Pontianak 78124 \\ Email : arit.prudynamic@yahoo.co.id
}

\section{Abstract}

The Dayak Ribun Tribe Society has natural resources that can be developed as a source of community income. Interaction with nature still exists today so there is a need for research on the types of plants that are used, the art forms that are made and the parts of the plants that are used by the Dayak Ribun Tribe of Gunam Village, Parindu District, Sanggau District as art crafts. The method used in this study is a survey method with interview techniques for taking respondents to snowball sampling. Retrieval of data or information is carried out directly by researchers on selected respondents, prospective respondents are determined by respondents who have been interviewed beforehand and continue to the next respondent. Respondents were obtained as many as 32 people. Data collection is done by observation, in-depth interviews, and documentation using a camera. The number of plant species used in Gunam Village as raw material for crafts and raw materials for musical instruments as many as 14 species from 9 families includes Areaceae, Gleicheniaceae, Poaceae, Thymelaeaceae, Apocynaceae, Dipterocarpaceae, Simaroubaceae, Fagaceae and Moraceae. The part of the plant that was used by the community in Gunam Village was found as many as 9 types of stems, 2 types of leaves, 2 types of seeds, 1 root, 1 type of fruit and 1 bark. There were two types of plants that were used by more than one plant organs namely Kemenyan or Aquilaria sp and keraci or Lithocarpus sp. Art forms that are used in the form of crafts and musical instruments. Crafts include key chains, clothes racks, chairs, rings, bracelets, takin, mats, hats, necklaces, drinking glasses, plates, clothes, bags, ropes, while musical instruments are sape

Keywords: Dayak Ribun, Ethnobotany, Utilization of plant,

\section{PENDAHULUAN}

Masyarakat Suku Dayak Ribun memiliki sumber daya alam yang dapat dikembangkan sebagai sumber pendapatan masyarakat. Interaksi terhadap alam masih ada hingga saat ini sehingga perlu adanya penelitian mengenai jenis-jenis tumbuhan yang dimanfaatkan, bentuk kesenian yang dibuat dan bagian tumbuhan yang dimanfaatkan oleh Suku Dayak Ribun
Desa Gunam Kecamatan Parindu Kabupaten Sanggau sebagai kerajinan seni. Tujuan penelitian ini adalah untuk mengetahui jenis tumbuhan, bagian tumbuhan dan bentuk kesenian yang dimanfaatkan oleh suku Dayak Ribun Desa Gunam Kecamatan Parindu Kabupaten Sanggau

\section{METODE PENELITIAN}

Metode yang digunakan dalam penelitian ini adalah metode survey 
dengan teknik wawancara pengambilan responden dilakukan secara snowball sampling. Pengambilan data atau informasi dilakukan secara langsung oleh peneliti pada responden terpilih. Waktu penelitian hingga selesai penyusunan skripsi selama 6 bulan. Calon responden ditentukan oleh responden yang telah diwawancarai sebelumnya dan berlanjut pada responden berikutnya. Responden diperoleh sebanyak 32 orang. Pengumpulan data dilakukan dengan teknik observasi, wawancara mendalam, dan dokumentasi dengan menggunakan kamera

\section{HASIL DAN PEMBAHSAN}

Berdasarkan hasil wawancara bersama masyarakat di Desa Gunam Kecamatan Parindu Kabupaten Sanggau diperoleh responden sebanyak 32 orang. Wawancara dilakukan untuk memperoleh data mengenai jenis tumbuhan yang dimanfaatkan sebagai kesenian di daerah tersebut. Jenis tumbuhan yang dimanfaatkan dapat dilihat pada Tabel 1.

Tabel 1. Jenis Tumbuhan yang Dimanfaatkan sebagai Kesenian di Desa Gunam Kecamatan Parindu (Types of Plants Used as Art in Gunam Village, Parindu District)

\begin{tabular}{|c|c|c|c|c|c|c|}
\hline No & $\begin{array}{l}\text { Nama } \\
\text { Umum }\end{array}$ & Nama Ilmiah & Famili & $\begin{array}{l}\text { Bagian Yang } \\
\text { Dimanfaatkan }\end{array}$ & $\begin{array}{l}\text { Cara } \\
\text { Pengolahan }\end{array}$ & $\begin{array}{l}\text { Macam } \\
\text { Kesenian }\end{array}$ \\
\hline 1 & Rotan Sega & $\begin{array}{l}\text { Calamus } \\
\text { axillaris Becc. }\end{array}$ & Areaceae & Batang & Dianyam & Kerajinan \\
\hline 2 & Resam & $\begin{array}{l}\text { Dicranopteris } \\
\text { linearis }\end{array}$ & Gleicheniaceae & Batang & Dianyam & Kerajinan \\
\hline 3 & $\begin{array}{l}\text { Bambu } \\
\text { Tulup }\end{array}$ & $\begin{array}{l}\text { Gigantochola } \\
\text { atter }\end{array}$ & Poaceae & Batang & Dianyam & Kerajinan \\
\hline 4 & $\begin{array}{l}\text { Pandan } \\
\text { Berduri }\end{array}$ & $\begin{array}{l}\text { Pandanus } \\
\text { tectorius }\end{array}$ & Areaceae & Daun & Dianyam & Kerajinan \\
\hline 5 & Jali & $\begin{array}{l}\text { Coix lacryma- } \\
\text { jobi }\end{array}$ & Poaceae & Biji & Dijahit & Kerajinan \\
\hline 6 & Kemenyan & Aquilaria sp & Thymelaeaceae & $\begin{array}{l}\text { Batang dan } \\
\text { Buah }\end{array}$ & Dipahat & Kerajinan \\
\hline 7 & Pulai & Alstonia spp & Apocynaceae & Batang & Dipahat & $\begin{array}{l}\text { Alat musik, } \\
\text { kerajinan }\end{array}$ \\
\hline 8 & $\begin{array}{l}\text { Meranti } \\
\text { Bunga }\end{array}$ & Shorea leprosula & Dipterocarpaceae & Batang & Dipahat & Alat musik \\
\hline 9 & $\begin{array}{l}\text { Pasak } \\
\text { Bumi }\end{array}$ & $\begin{array}{l}\text { Eurycoma } \\
\text { longifolia }\end{array}$ & Simaroubaceae & Akar & Dipahat & Kerajinan \\
\hline 10 & $\begin{array}{l}\text { Kelapa } \\
\text { Sawit }\end{array}$ & $\begin{array}{l}\text { Elaeis } \\
\text { guineensis }\end{array}$ & Arecaceae & Daun & Dianyam & Kerajinan \\
\hline 11 & Kapoak & $\begin{array}{l}\text { Artocarpus } \\
\text { elasticus }\end{array}$ & Moracear & Kulit Batang & Dianyam & Kerajinan \\
\hline 12 & Rotan Obut & $\begin{array}{l}\text { Calamus } \\
\text { trachycoleus } \\
\text { Beccari }\end{array}$ & Areaceae & Batang & Dianyam & Kerajinan \\
\hline 13 & Rotan Padi & $\begin{array}{l}\text { Calamus caesius } \\
\text { Blume }\end{array}$ & Areaceae & Batang & Dianyam & Kerajinan \\
\hline 14 & Keraci & Lithocarpuse $s p$ & Fagaceae & Batang dan Biji & Dianyam & Kerajinan \\
\hline
\end{tabular}


Berdasarkan hasil wawancara diperoleh 14 jenis tumbuhan dari 9 famili yang dimanfaatkan oleh masyarakat di Desa Gunam Kecamatan Parindu Kabupaten Sanggau. Pemanfaatan tumbuhan sebagai kesenian yang ditemukan berupa kerajinan dan alat musik.
Tumbuhan yang dimanfaatkan sebagai kerajinan diperoleh sebanyak 12 jenis sedangkan tumbuhan yang dimanfaatkan sebagai alat musik diperoleh 2 jenis tumbuhan. Macammacam produk kesenian yang dihasilkan dapat dilihat pada Tabel 2 di bawah ini:

Tabel 2. Produk kesenian yang dihasilkan (Art products produced)

\begin{tabular}{|c|c|c|}
\hline Jenis tumbuhan & Kerajinan & Alat musik \\
\hline Rotan loa & $\begin{array}{l}\text { - Gantungan kunci } \\
\text { - Rak serba guna } \\
\text { - Kursi }\end{array}$ & - \\
\hline Resam & $\begin{array}{l}\text { - Cincin } \\
\text { - Gelang }\end{array}$ & - \\
\hline Bambu Tulup & - Takin & - \\
\hline Pandan berduri & $\begin{array}{l}\text { - Tikar } \\
\text { - Topi }\end{array}$ & - \\
\hline Bancing ompah & - Kalung & - \\
\hline Kemenyan & - Aksesoris baju adat & - \\
\hline Pulai & - Sauvenir sape & - Sape'e \\
\hline Meranti bunga & - & - Sape'e \\
\hline Pasak bumi & - Gelas minum & - \\
\hline Kelapa sawit & - Piring & - \\
\hline Kapoak & $\begin{array}{l}\text { - Baju } \\
\text { - Tas } \\
\text { - Tali } \\
\text { - Sauvenir }\end{array}$ & - \\
\hline Rotan obut & - Takin & - \\
\hline Rotan padi & $\begin{array}{l}\text { - Kursi } \\
\text { - Gelang }\end{array}$ & - \\
\hline Keraci & $\begin{array}{l}\text { - Sauvenir gantungan kunci } \\
\text { - Aksesoris baju adat }\end{array}$ & - \\
\hline
\end{tabular}

Berdasarkan hasil penelitian, pemanfaatan tumbuhan yang dilakukan oleh masyarakat Desa Gunam untuk satu jenis tumbuhan tidak hanya dimanfaatkan untuk satu jenis karya melainkan banyak jenis. Sebagai contoh Rotan loa digunakan sebagai Pemanfaatan tumbuhan sebagai kerajinan dan alat musik pengolahannya bervariasi dari yang mudah hingga sulit selain itu ada juga yang memerlukan waktu yang lama. Hasil penelitian menunjukan pada masyarakat Desa Gunam pengolahan tumbuhan terdiri dari 12 jenis tumbuhan antara lain

1. Rotan loa

Rotan loa atau dengan nama ilmiah di sebut Calamus axillaris Bec 
dimanfaatkan olehmasyarakat Desa Gunam sebagai bahan baku kursi, rak serba guna dan gantungan kunci. Pengolahan rotan loa sebagai kursi yaitu dengan mengambil beberapa batang rotan loa dengan ukuran diameter kurang lebih 3-5 cm yang digunakan sebagai sandaran pada kursi, dudukan kursi menggunakan diameter 1-3 cm. Sebelum pengolahan menjadi kursi semua bahan yaitu tali dari rotan loa, resam dan bambu harus melalui proses pengeringan. Pengeringan menggunakan panas matahari dengan waktu hingga 1 minggu. Pengeringan bertujuan meningkatkan ketahanan dan kelenturannya agar mudah dianyam. Setelah proses pengeringan selesai tahap selanjutnya yaitu

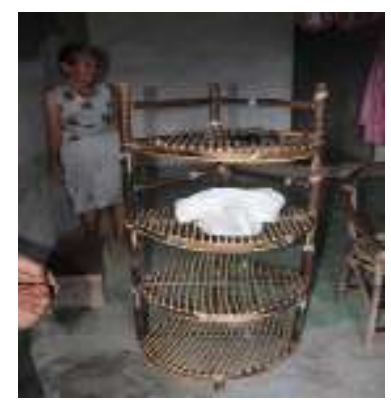

Gambar (a) menganyam rotan loa dan menghubungkannya dengan tali dari resam yang telah dipotong dengan ukuran 1-2 $\mathrm{cm}$ proses anyaman hingga jadi kursi memerlukan waktu 3 hari. Pengolahan rotan loa sebagai rak serba guna tidak jauh berbeda dengan pembuatan kursi perbedaanya hanya di ukuran panjang rotan. Pengolahan rotan loa untuk gantungan kunci dengan cara membelah rotan loa menjadi ukuran 1-2 $\mathrm{cm}$ kemudian batang yang telah dibelah di potong memanjang, proses pengolahannya yaitu dengan teknik anyaman. Satu gantungan kunci hanya memerlukan waktu 1 hari. Hasil kerajinan dari rotan loa dapat di lihat pada Gambar 1.

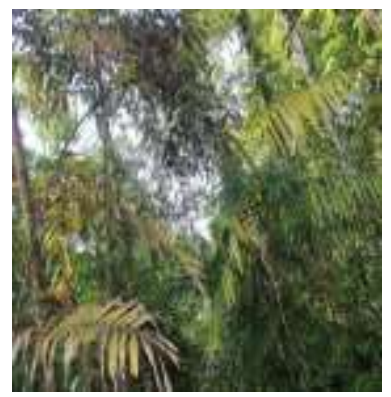

Gambar (b)

Gambar 1. (a) rak serba guna (Versatile shelves) dan (b) tumbuhan rotan loa (rotan loa plants and)

Habitat rotan loa meliputi dataran rendah dan hutan gambut, penyebarannya meliputi Kalimantan hingga Sarawak Malaysia. Rotan loa memiliki ciri batang berduri dan batang lebih besar dari jenis rotan lainnya. (Anonim, 2017)

2. Resam

Pada masyarakat Desa Gunam tumbuhan resam dimanfaatkan sebagai kerajinan tangan yang memiliki nilai seni dan keunikan. Resam dimanfaatkan sebagai cincin dan gelang. Proses pengolahannya dengan teknik anyaman. Bagian yang dimanfaatkan adalah batang resam yang telah dibuang kulit luarnya. Proses pengolahnya hinga menjadi cincin dan gelang yaitu dengan mengambil bagian dalam batang kemudian batang bagian dalam resam di rendam selama 3 hari menggunakan air bersih. Untuk menambah keunikan biasanya masyarakat di Desa Gunam merendam batang dengan akar yang 
dapat menghasilkan warna seperti akar tela unggu. Setelah direndam batang resam disimpan ditempat kering selama 1 hari hingga air dalam batang resam kering. Setelah proses pengeringan selesai dilanjutkan dengan menganyam batang resam, anyaman yang dilakukan

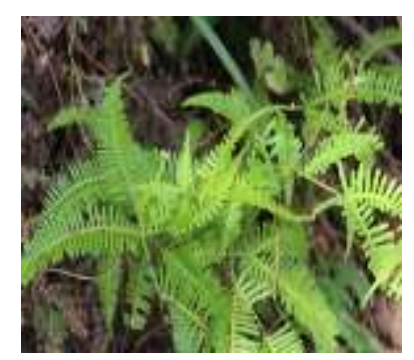

Gambar 2. (a) tumbuhan resam (Resam Plants) (b) Resam merupakan salah satu tanaman yang penyebarannya meliputi seluruh dunia kecuali daerah bersalju dan lautan. Cenderung hidup di areal yang miskin hara, resam juga merupakan salah satu tumbuhan berpembuluh yang reproduksinya menggunakan spora. (Anonim, 2017) Bambu Tulup

Bambu tulup atau dalam bahasa Dayak Gunam disebut bambu tulup adalah salah satu jenis bambu dari famili Poaceae. Proses pengolahannya tergolong tidak rumit, dari pengumpulan bahan baku hingga menjadi sebuah takin kira-kira memerlukan waktu 1 minggu. Tahapan pembuatan takin dari bahan baku bambu tulup yaitu dengan memotong bambu sepanjang ukuran batang, rata-rata panjang batang bambu ini berkisar 3-5 meter. Bambu yang telah dipotong kemudian masyarakat Desa Gunam berkisar 3-5 batang yang disatukan hingga membentuk gelang dan cincin. Proses anyaman yang dilakukan memerlukan waktu kurang lebih 3 jam, semakin banyak batang resam yang dianyam semakin lama proses pengolahannya.

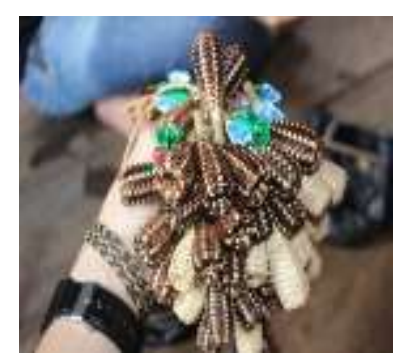

(b) aksesoris dari resam (accessories from resam) dibersihakn dari daun dan ranting-ranting. Selanjutnya bambu tersebut dibelah dan diraut dengan lebar 1-2 cm. Setelah itu bambu langsung dianyam membentuk wadan sebagai media penyimpanan, bahan tambahan untuk membuat takin yaitu dengan rotan sebagai lingkaran permukaan dan kayu untuk penyangga bawah. Selain itu untuk menyatukan antara rotan dan bambu diperlukan tali dari bahan bahan rotan yang telah di potong dengan lebar 1$2 \mathrm{~cm}$. Takin di Desa Gunam digunakan sebagai penyimpanan padi, hasil pertanian seperti jagung, kacang, dan lain sebagainya (Gambar 3). Takin di daerah tersebut biasanya diproduksi sesuai permintaan masyarakat, harga yang ditawarkan bervariasi mulai Rp50.000 hingga Rp200.000 tergantung tingkat kerumitannya 


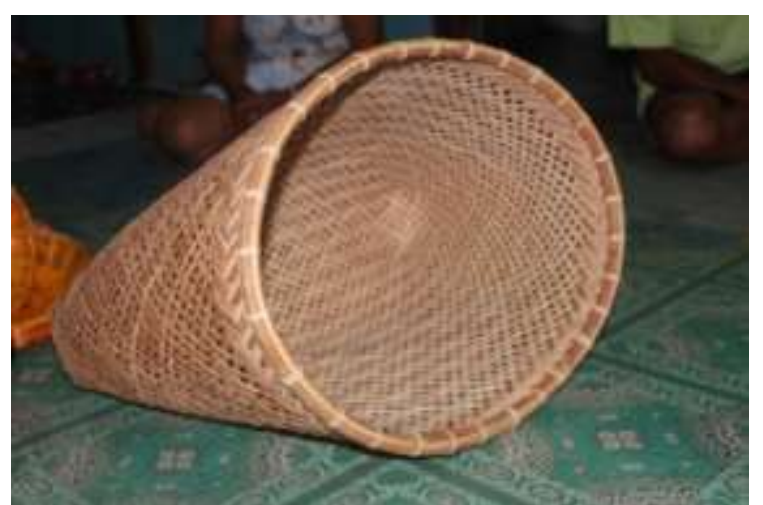

Gambar 3. Hasil kerajinan bahan baku bambu tulup (The results of handicrafts made from bamboo tulup)

Bambu tulup merupakan salah satu jenis bambu yang terdapat di Indonesia, berdasarkan pengamatan di lapangan bambu tulup hidup di dataran rendah hingga ketinggian 120 mdpl. Bambu ini berukuran kecil dan memiliki kelenturan yang baik sehingga masyarakat banyak memanfaatkan sebagai bahan baku takin. (Anonim, 2017 )

\section{Pandan berduri}

Pandan berduri adalah salah satu jenis suku pandan-pandan yang dapat dijumpai di rawa hingga pegunungan. Masyarakat pedalaman di Desa Gunam telah menggunakan pandan berduri sebagai alternatif pembuatan tikar dan topi (Gambar 4). Berdasarkan keterangan dari beberapa responden, pengetahuan pembuatan tikar dan topi dilakukan turun temurun. Pengolahan pandan berduri sebagai tikar dan topi tidak begitu rumit. Dari pengumpulan hingga menjadi tikar dan topi memerlukan waktu 1 hingga 2 minggu. Tahapan awal yaitu pengumpulan pandan berduri, pandan berduri diambil daunnya kemudian dipotong pangkal dan ujung, pemotongan berdasarkan ukuran yang telah ditentukan yaitu apabila salah satu dipotong sepanjang 2 meter, potongan yang lain juga 2 meter. Hal tersebut diterapkan agar tidak rumit saat penganyaman. Pandan berduri yang telah dipotong kemudian dibelah kirakira 3-4 cm, setelah itu pandan dijemur hingga kering, penjemuran dilakukan agar daun pandan tidak robek saat dianyam. Pembuatan tikar dilakukan dengan satu arah yang diawali dengan pembuatan sudut pertama, kemudian dilanjutkan dengan menganyam hingga membentuk persegi. Tikar dalam pemanfaatanya memilki banyak fungsi seperti media menjemur padi, sebagai alas untuk tidur dan lain sebagainya. Selain tikar pandan berduri juga digunakan sebagai bahan baku pembuatan topi, proses pembuatan topi yaitu dengan memotong pandan berduri dengan panjang $50 \mathrm{~cm}$ dan lebar $4-5 \mathrm{~cm}$. Pertama-tama yang harus dilakukan adalah membuatan lingkaran seukuran kepala sebagai penyangga saat dipakai. Kemudian membentuk daun pandan menyerupai kerucut ujung lingkaran dihubungkan dengan rotan dengan diameter 30-40 cm. Pembuatan topi dari bahan baku pandan hanya memerlukan 
waktu kira-kira 3-5 jam. Topi digunakan sebagai pelindung saat panas dan hujan, kebanyakan masyarakat Desa Gunam

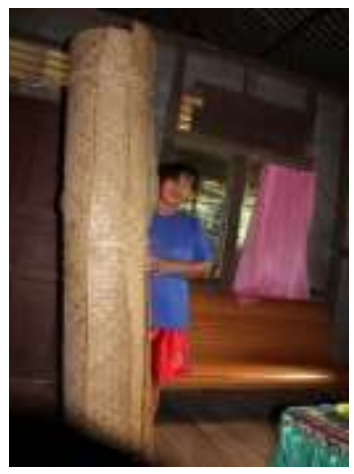

Gambar 4. Hasil kerajinan dari bahan baku Pandan Berduri (Handicrafts from Pandan Berduri raw

Pandan berduri merupakan salah satu spesies dari pandanaceae yang penyebarannya meliputi daerah rawa gambut dan dataran rendah hingga dataran tinggi, varietas tertentu ada yang hidup di daerah pantai-pantai. (Anonim, 2017 )

4. Jali

Jali atau dalam bahasa Dayak Gunam disebut bancing ompah merupakan salah satu jenis tanaman dari suku padi-padian atau Poaceae. Bancing ompah memiliki biji yang keras dan berbentuk rumpun.

Pada masyarakat Desa Gunam tumbuhan ini dimanfaatkan sebagai bahan pembuatan kalung dan gelang (Gambar 5). Biji bancing ompah berdasarkan kepercayaan masyarakat setempat memiliki nilai mistis. Di Desa materials)

menggunakan topi ini saat melakukan aktifitas rutin seperti berkebun dan berladang.

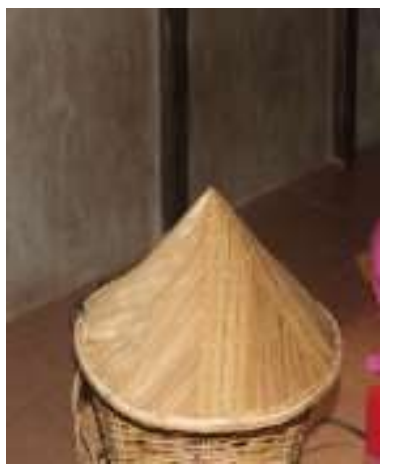

pengolahaan biji ini yaitu dengan mengambil biji bancing ompah yang telah tua kemudian di kedua pangkal biji diberi lubang untuk memasukan tali. Setelah lubang terbentuk kemudian menyatukan biji-biji dengan memasukan tali kedalam ujung pangkal yang telah diberi lubang. Biasanya masyarakat Desa gelang kepada anak yang masih kecil, hal tersebut dipercaya dapat menangkal rohroh jahat. Karena masyarakat Desa Gunam percaya anak kecil cenderung lebih disukai makhluk halus.

Berbeda dengan hasil penelitian Nurmala (2009) yang mengolah dari biji jali sebagai bahan bubur jali, tape, dan kue-kue yang menggunakan tepung jali sebagai tepung campuran Gunam memberikan kalung ataupun 


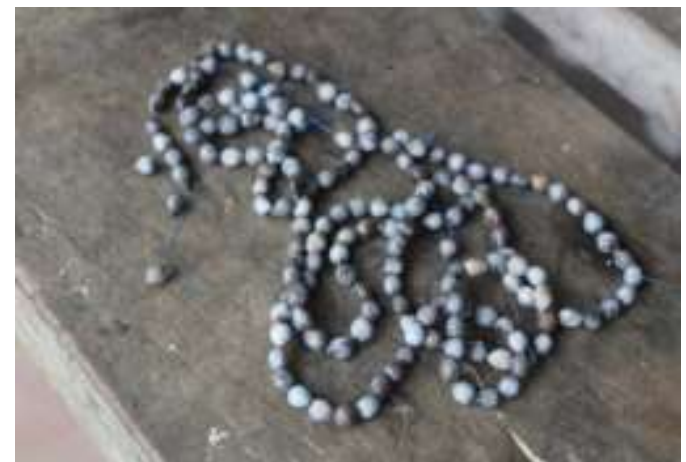

Gambar 5. Kesenian dari Biji Jali (Art of Jali Seeds)

Jali merupakan tanaman perdu semusim yang hidupnya di lahan kering. Tumbuhan ini toleran terhadap banjir 5. Kemenyan

Kemenyan atau lebih dikenal dengan sebutan gaharu merupakan salah satu jenis tumbuhan dari famili Thymelaeaceae. Pada masyarakat Desa Gunam tumbuhan ini dimanfaatkan sebagai kerajinan ukiran. Bagian yang dimanfaatkan yaitu batang gaharu. Proses pengolahannya yaitu dengan mengambil batang gaharu yang berdiameter kira-kira $20 \mathrm{~cm}$. Dan dan kekurangan hara. Jali dapat hidup di rawa dan dataran tinggi hingga ketinggian 2000 mdpl. (Anonim, 2017 ) dipotong berdasarkan ukuran tertentu kemudian diukir dengan menggunakan pahat. Biasanya masyarakat di Desa Gunam membentuk kayu gaharu menjadi kepala burung enggang (Gambar 6). Pemilihan kayu gaharu sebagai bahan baku membuat kepala burung enggang dikarenakan masyarakat percaya kayu gaharu memiliki nilai spritual tinggi atau nilai mistik

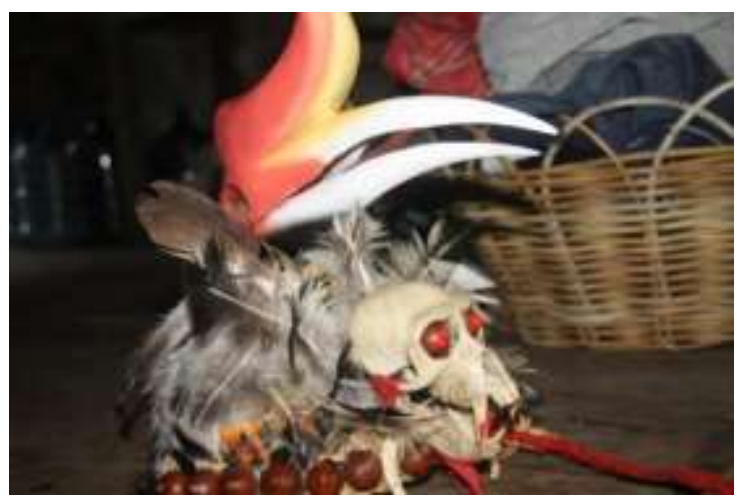

Gambar 6. Kesenian dari batang Gaharu (Art from the stem of Gaharu)

Gaharu memiliki tinggi batang mencapai $40 \mathrm{~m}$, dengan diameter lebih dari $60 \mathrm{~cm}$. Batangnya lurus, tidak berbanir. Kulit batangnya halus, dengan warna coklat keputih-putihan. Tajuknya bulat, lebat, dengan percabangan horisontal. Daunnya tunggal, berseling, tebal, bentuknya jorong hingga jorongmelanset, dan panjang. Tajuknya lebat, bulat, percabangannya horisontal. Perbungaannya berbentuk payung, membentuk cabang, tumbuh pada ketiak daun. Bunganya kecil, berwarna hijau/kuning kotor, dan berbulu jarang. Buahnya berbentuk telur terbalik, dan berbulu halus. (Anonim, 2017 ) 


\section{Pasak Bumi}

Pasak bumi (Eurycoma Longifolia Jack) merupakan salah satu tumbuhan obat yang belum banyak dikembangkan, padahal tanaman ini memiliki banyak khasiat, seperti ekstrak akar Eurycoma longifolia Jack dapat meredakan nyeri pada lambung (Kosala, 2010), selain itu akar pasak bumi juga berfungsi sebagai afrodisiak atau obat kuat (Nainggolan dan Simanjuntak, 2005) dan imunomodulator melalui peningkatan aktivitas IL-12. , 2005). Pada masyarakat di Desa Gunam akar pasak bumi dipahat dan dibentuk seperti gelas kemudian dimasukan air, sehingga kandungan diakar pasak bumi terlarut dalam air (Gambar 7). Air yang disimpan didalam gelas akar pasak bumi dipercaya dapat menghilangkan segala jenis penyakit. Menurut (Arifah, 2014) Kuasinoid dari ekstrak akar pasak bumi, memiliki aktivitas sebagai antioksidan

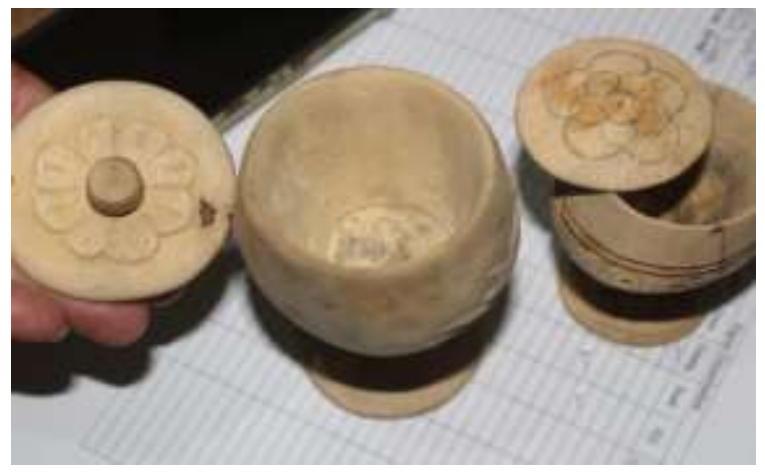

\section{Gambar 7. Gelas dari akar pasak bumi (Glass from the root of the earth)}

Persebaran pasak bumi cukup luas mencakup Bima, Thailand, Laos, Kamboja, Indocina, Semenanjung Malaya, Kalimantan, dan Sumatera. Pasak bumi tumbuh di hutan dataran rendah pada tanah yang miskin hara, berpasir, dan bersifat asam. Pasak bumi dijumpai di berbagai jenis hutan, mulai hutan primer, hutan sekunder, hutan pantai, hutan kerangas sampai hutan Dipterocarpaceae campuran. Pasak bumu tumbuh pada ketinggian tempat di bawah mdpl. (Anonim, 2017)

7. Kelapa sawit

Kelapa sawit merupakan salah satu jenis tanaman komoditi perkebunan yang saat ini menjadi primadona di kalangan masyarakat. Tanaman dengan nama ilmiah Elaeis guineensis tersebut merupakan salah satu penghasil minyak mentah atau Crude Palm Oil (CPO) dari buah yang dihasilkan. Selain buah yang dimanfaatkan sebagai bahan baku minyak mentah, pada masyarakat Desa Gunam memanfaatkan daun kelapa sawit sebagai piring. Piring yang terbuat dari tulang daun kelapa sawit digunakan sebagai tempat nasi dan makanan lainnya. Pengolahannya dengan cara dianyam, langkah pertama membuat piring dari daun kelapa sawit yaitu dengan mengambil daun kelapa sawit, dan menyisakan tulang daun sehingga. Setelah itu potong berdasarkan ukuran daun lainnya agar daun sama panjang. Kemudian tulang daun tersebut langsung dianyam dengan bentuk menyerupai piring (Gambar 8) 


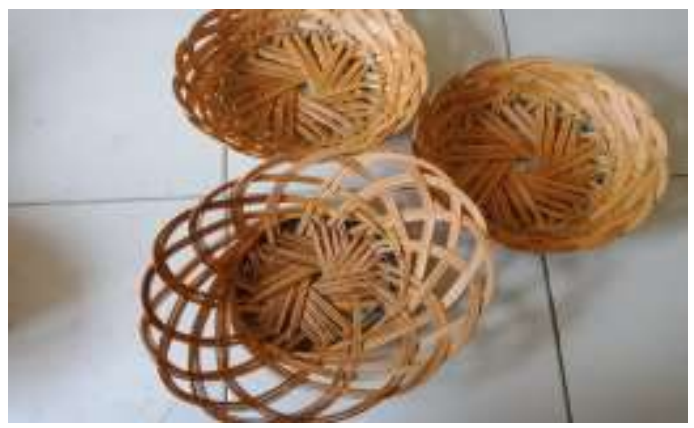

Gambar 8. Kerajinan dari tulang daun kelapa sawit (Crafts from the bones of palm oil leaves)

Di Indonesia sawit pertama kali di tanam di kebun raya bogor pada tahun 1848. Tanaman sawit berasal dari Portugis dan Afrika. Kelapa sawit dapat hidup di daerah rawa gambut dan dataran tinggi. Namun untuk pertumbuhannya sangat baik bila ditanam di daerah rawa gambut. (Anonim, 2017)

8. Kapoak

Kapuak atau Artocarpus elasticus merupakan salah satu jenis tumbuhan dari famili Moraceae, kapuak berkerabat dekat dengan cempedak, nangka dan sukun. Pada masyarakat Desa Gunam tumbuhan ini dimanfaatkan kulit batang sebagai bahan baku kerajinan yaitu untuk membuat baju tradisional, tas, tali dan souvenir. Pengolahan baju tradisional dan pengolahan tas dengan bahan baku kulit batang kapuak yaitu dengan mengambil kulit batang kapuak yang berdiameter diatas $30 \mathrm{~cm}$. Pengambilan kulit batang kapuak dengan cara menebang pohon kapuak. Setelah ditebang batang pohon kapuak di potong dengan ukuran 1 meter, lalu diambil kulit batangnya. Kemudian kulit batang paling luar dipisahkan dari kulit dalamnya dengan cara di pukul menggunakan pemukul dari kayu. Setelah bersih kulit kapuak di jemur, kulit kapuak dijemur selama 3-7 hari sampai kulit batang kering, tahapan selanjutnya membentuk kulit kapuak dan memotong menjadi ukuran tertentu dan menyerupai bentuk tertentu seperti baju tradsional dan tas. Pada masyarakat Desa Gunam hasil olahan kulit kapuak dapat dilihat pada (Gambar 9)
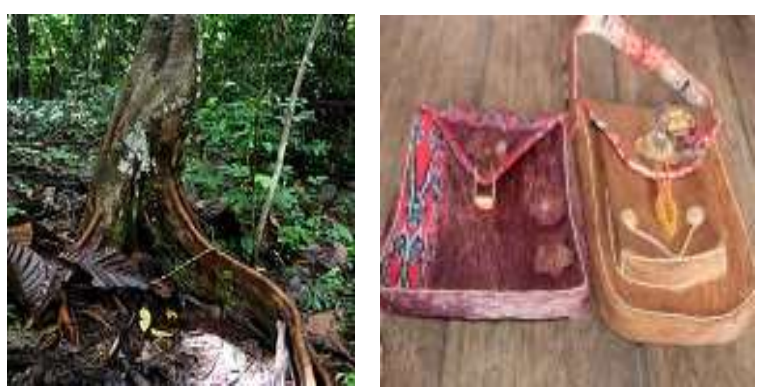

Gambar 9. Pohon kapuak dan produk dari bahan kulit kayu kapuak Kapuak trees and products from kapuak bark materials 
Kapuak merupakan tumbuhan berumah satu (monoecious), berukuran sedang, dengan tinggi pohon bisa mencapai antara 45-65 meter. Diameter batang antara diameter 1,2 - 2 meter, dengan batang bagian bawah yang bebas 9. Rotan obut

Pada masyarakat Desa rotan obut dimanfaatkan sebagai bahan baku membuat takin (Gambar 10), takin merupakan salah satu hasil kerajinan tangan berbentuk seperti tong penampungan. Takin digunakan sebagai pengangkut hasil pertanian seperti timun, padi, dan lain-lain. Takin terbuat dari rotan obut cara pengolahannya yaitu cabang hingga mencapai 30-an meter. Kulit pohon berwarna abu - abu gelap hingga kelabu kecokelatan sedang bagian dalamnya kekuningan hingga cokelat pucat, teksturnya halus atau agak bersisik. (Anonim, 2017 )

dengan membersihkan rotan dari kulit luar, setelah itu memotong rotan obut berukurn 1-2 meter dengan lebar 2-3 cm. Setelah dipotong kemudian dijemur 3-7 hari. Langkah selanjutnya yaitu membuat anyaman. Setelah anyaman selesai langakah terakhir yaitu menambahakan rotan di atas permukaan takin dan menambah kayu dudukan di bawah takin.

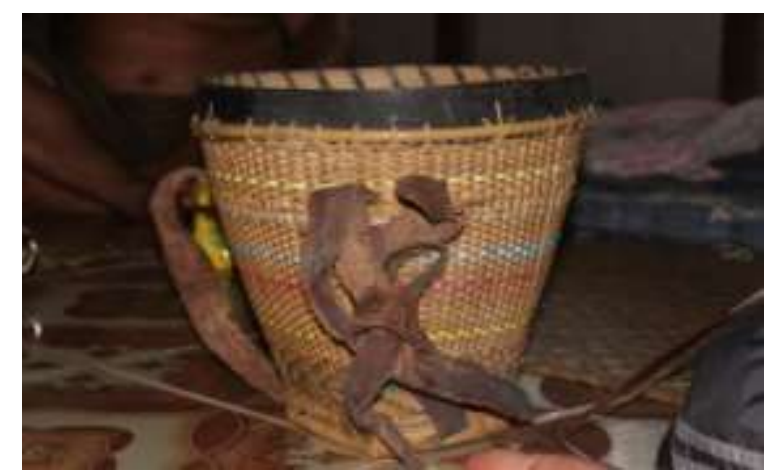

Gambar 10. Takin dari bahan baku Rotan Obut Takin is made from Rotan Obut.

Persebaran rotan obut di Kalimantan (endemik). Perawakan berumpun, memanjat, tinggi mencapai $25 \mathrm{~m}$. Diameter batang pelepah daun 20 - $40 \mathrm{~mm}$ (tanpa pelepah daun 4 - 15 $\mathrm{mm}$ ), panjang ruas $15-30 \mathrm{~cm}$; pelepah daun hijau muda, ditumbuhi 2 tipe duri yaitu duri besar yang tersebar, coklat ujungnya dan hijau pangkalnya, panjang $10 \mathrm{~mm}$, dengan duri - duri pendek banyak sekali (rapat), panjang $2 \mathrm{~mm}$, tersebar di antara duri-duri besar. Lutut jelas, warna hijau, berduri pendek rapat; Okrea jelas, tidak berduri; Daun bersulur, panjang daun $150 \mathrm{~cm}$, panjang sulur $153 \mathrm{~cm}$, ditumbuhi duri. Tangkai daun $2 \mathrm{~cm}$ panjangnya. Helaian anak daun berbentuk lanset atau melanset, berukuran $21-32 \mathrm{~cm} \times 1,5-3,8 \mathrm{~cm}$, helaian anak daun warna hijau, jumlah anak daun 31 terletak di kanan kiri rakis, anak daun tersusun menyirip tidak teratur dan bagian pagkalnya memeluk batang (Anonim, 2017)

10. Rotan padi

Rotan padi atau lebih di kenal rotan sega adalah salah satu jenis rotan yang dimanfaatkan oleh masyarakat di Desa Gunam sebagai bahan baku pembuatan kursi dan gelang (Gambar 11). Pengolahan rotan padi sama halnya dengan pengolahan rotan lainnya. Rotan 
sega memiliki permukaan kulit yang berduri dan berwarna kuning mengkilat. Sehingga rotan ini dipilih masyarakat sebagai bahan baku kursi dan gelang. Bahan tambahan untuk membuat kursi masyarakat Desa Gunam menggunakan rotan roa sebagai sandaran dan kaki kursi. Pemanfaatan Rotan Sega juga pernah dikemukankan oleh Mogea (2002) bahwa jenis tanaman rotan yang dimanfaatkan sebagai bahan anyaman rotan dunia adalah jenis Rotan Taman dan jenis Rotan Sega.

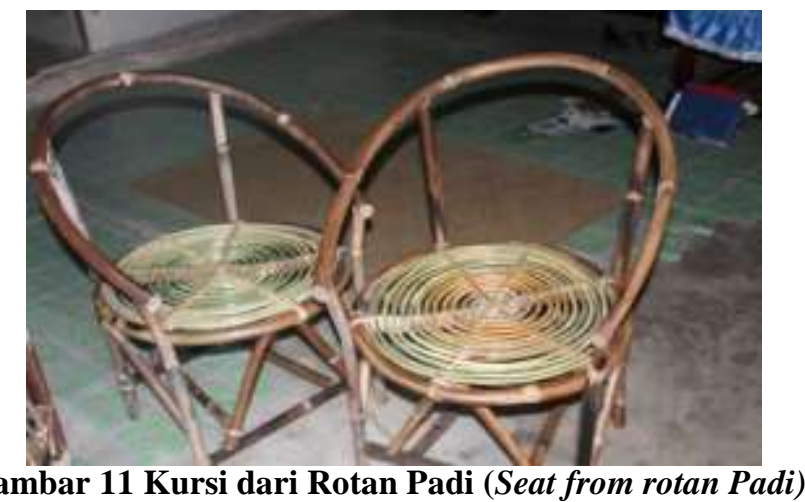

Sebagian besar rotan berasal dari hutan di Indonesia, seperti Sumatra, Jawa, Borneo, Sulawesi, dan Nusa Tenggara. Indonesia memasok $70 \%$ kebutuhan rotan dunia. Sisa pasar diisi dari Malaysia, Filipina, Sri Lanka, dan Bangladesh. Rotan padi di Indonesia deikenal sebagai Rotan Sega. Saat pengamatan rotan padi ditemukan di daerah rawa gambut. (Anonim, 2017)

11. Keraci.

Keraci pada masyarakat Desa Gunam dimanfaatkan sebagai bahan baku pembuatan alat musik sape'e, soufenir dan sebagainya. Bagian yang dimanfaatkan dari tumbuhan ini adalah batang. Pengolahannya yaitu pilih batang keraci yang berdiameter kurang lebih $20 \mathrm{~cm}$ ke atas setelah itu potong dengan panjang 1-2 meter setelah itu buang kulit epidermis batang hingga menyisakan kulit dermis batang. Kemudian belah batang menjadi dua bagian, langkah selanjutnya melakukan pengukiran hingga terbentuk seperti sape'e.

Pengolahan Tumbuhan sebagai Alat Musik

Pulai adalah salah satu jenis tumbuhan dari famili Apocynaceae. Kayu pulai termasuk dalam kelas awet $\mathrm{V}$ dan kelas kuat IV - V dengan berat jenis rata-rata $0,38 \mathrm{~g} / \mathrm{cm} 3(0,27-0,49 \mathrm{~g} / \mathrm{cm} 3$ ) Mashudi (2014). Tumbuhan ini dapat hidup di dataran tinggi hingga dataran rendah. Pada masyarakat Desa Gunam tumbuhan ini dimanfaatkan sebagai bahan baku untuk membuat alat musik sape'e. Sape'e merupakan alat musik tradisional dayak di Kalimantan yang berasal dari sub suku Dayak Iban. Pengolahan batang pulai sebagai alat musik sape'e yaitu diawali dengan mengambil batang pulai yang telah berdiameter $20 \mathrm{~cm}$ ke atas. Setelah itu batang pulai di potong memanjang sekitar 1 meter membentuk kayu log. Kemudian log kayu tersebut di potong 
untuk mendapatkan ukuran kurang lebih 50-100 cm dan panjang 1 meter. Langkah selanjutnya yaitu membuat bagian senar bawah dan atas.selain itu dilakukan juga ukiran motif dan aksesoris khas dayak untuk menambah nilai seni pada alat musik ini, setelah itu dilakukan pengecatan menggunakan mesin (Gambar 12). Tahapan finishing yaitu memasang senar gitar yang berjumlah 3 tali.

\section{Gambar 12. Proses Pembuatan Sape (Sape making process)}

Meranti Bunga memiliki bentuk batang silindris dengan permukaan kulit beralur dalam, Kulit beralur berwarna coklat. Kayu kerwarna kuning dan beralur. Memiliki damar berwarna bening. Memiliki banir papan dengan tinggi mencapai $5 \mathrm{~m}$. Pohon berukuran besar dengan tinggi mencapai $75 \mathrm{~m}$ dengan diameter mencapai $160 \mathrm{~cm}$. Daun berbentuk ovate berukuran 5-13 $\mathrm{cm} \times 2-6 \mathrm{~cm}$. Berat jenis batangnya berkisar 400-815 kg/m3. Biasa ditemukan di daerah yang bergelombang dengan permukaan tanah liat. (Anonim, 2017 ) Meranti bunga pada masyarakat Desa Gunam dimanfaatkan kayunya sebagai material membuat alat musik sape'e. Berdasarkan penelitian menyebutkan meranti bunga memiliki berat jenis $0,5 \mathrm{~g} / \mathrm{cm}^{3}-0,81 \mathrm{~g} / \mathrm{cm}^{3}$ sehingga kayu ini tergolong dalam jeni kayu kelas III. Kayu kelas III berpotensi sebagai bahan baku pertukangan, mebel, kayu lapis dan funiture. Tahapan pembuatan kayu meranti bunga sebagai alat musik sape'e sama halnya dengan pembuatan alat musik sape'e dari kayu pulai. Tidak ada perlakuan yang berbeda antara kayu tersebut.

\section{Bagian Tumbuhan yang Dimanfaatkan}

Bagian tumbuhan yang dimanfaatkan oleh masyarakat di Desa Gunam yang ditemukan yaitu batang sebanyak 9 jenis, daun sebanyak 2 jenis, biji sebanyak 2 jenis, akar sebanyak 1 jenis, buah sebanyak 1 jenis dan kulit batang sebanyak 1 jenis. Terdapat dua jenis tumbuhan yang dimanfaatkan lebih dari satu organ tumbuhan yaitu Kemenyan atau Aquilaria $s p$ dan keraci atau Lithocarpus sp. Aquilaria $\mathrm{sp}$ dimanfaatkan batang dan buah sebagai kerajinan dan souvenir sedangkan Lithocarpus sp dimanfaatkan sebagai bahan material dan souvenir. Ditinjau lebih lanjut pemanfaatan batang lebih banyak diantara bagian tumbuhan 
lainnya. Rincian lengkap dapat dilihat pada Gambar 13

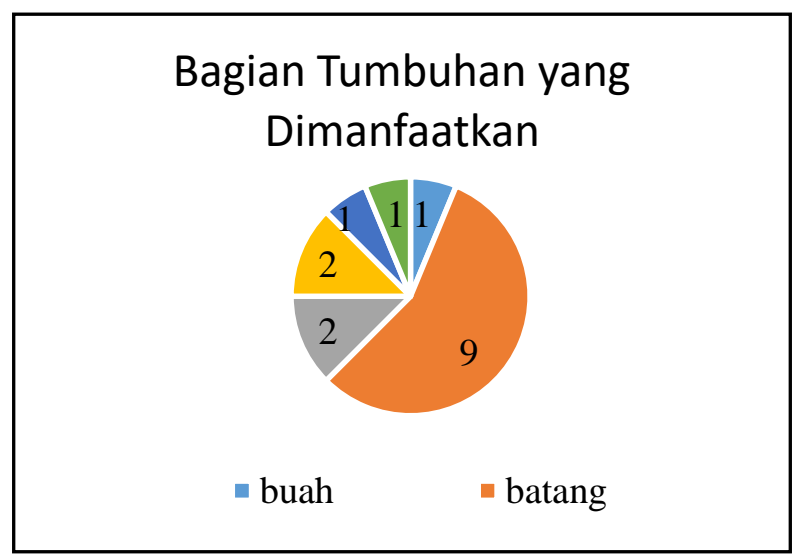

Gambar 13. Diagram Bagian Tumbuhan yang Dimanfaatkan di Desa Gunam (Diagram of Parts of Plants Used in Gunam Village)

\section{KESIMPULAN}

Jumlah jenis tumbuhan dimanfaatkan di Desa Gunam sebagai bahan baku kerajinan dan bahan baku alat musik sebanyak 14 jenis dari 9 famili meliputi Areaceae, Gleicheniaceae, Poaceae, Thymelaeaceae, Apocynaceae, Dipterocarpaceae, Simaroubaceae, Fagaceae dan Moraceae. Bagian tumbuhan yang dimanfaatkan oleh masyarakat di Desa Gunam yang ditemukan yaitu batang sebanyak 9 jenis, daun sebanyak 2 jenis, biji sebanyak 2 jenis, akar sebanyak 1 , buah sebanyak 1 jenis dan kulit batang sebanyak 1. Terdapat dua jenis tumbuhan yang dimanfaatkan lebih dari satu organ tumbuhan yaitu Kemenyan atau Aquilaria $s p$ dan keraci atau Lithocarpus sp. Hasil kesenian yang dimanfaatkan berupa kerajinan dan alat musik. Kerajinan meliputi gantungan kunci, rak pakaian, kursi, cincin, gelang, takin, tikar, topi, kalung, gelas minum, piring, baju, tas, tali, sedangkan alat musik berupa sape.

\section{UCAPAN TERIMAKASIH}

Penulis mengucapkan terimakasih kepada keluarga besar Nggadas yang senantiasa memberikan motivasi dan bantuan finansial serta kepada temanteman yang selama ini selalu memberikan semangat penuh sehingga penulis dapat menyelesaikan penelitian ini

\section{DAFTAR PUSTAKA}

Anonim. 2017. Asianplant.net [diunduh, 20 Oktober 2018)

Arifah, N.A., Nurkhasanah. 2014. Efek Fraksi Etil Asetat Ekstrak Etanol Akar Pasak Bumi (Eurycoma Longifolia, Jack) Terhadap Aktivitas Fagositosis Makrofag Secara In Vitro. Pharmaciana. 01(04). Yogyakarta.

Kosala K. 2010. Uji Efek Proteksi Akar Pasak Bumi (Eurycoma longifolia Jack) Terhadap Ulkus Lambung Tikus yang Diinduksi dengan Ligasi Pilori. Jurnal Media Sains. 2: 20853548

Mashudi., Adma,H.A dan Yuskianti,V. 2014. Pulai (Alstonia spp) untuk Bahan Barang kerajinan. IPB Press.Bogor-Indonesia. 
Mogea JP. 2002. Rotan di Taman Nasional Gunung Halimun dan Prosper Budidayanya di Desa Cisungsang Lebak Banten. Berita Biologi 6(1)

Nurmala, T. (2009).Prospek Jali (Coixlacryma-jobi L.) sebagai Pangan Serealia. Gramedia : Jakarta.
Nainggolan. O dan JW. Simanjuntak. 2005. Pengaruh Ekstrak Ethanol Akar Pasak Bumi Terhadap Perilaku Seksual Mencit Putih. Cermin Dunia Kedokteran. 146:147. 